\title{
Comunicação
}

[Communication]

\section{Nutrição enteral precoce com glutamina em cães com gastrenterite hemorrágica pelo parvovirus canino}

[Early enteral nutrition with glutamine in dogs with hemorrhagic gastroenteritis by canine parvovirus]

\author{
P.R.S. Costa, L.G. Conceição, M.A.F. Lopes \\ Departamento de Veterinária - UFV \\ Av. P. H. Rolfs, s/n \\ 36570-000 - Viçosa, MG
}

A parvovirose canina é a causa mais frequente de diarreia hemorrágica de origem infecciosa em cães até os seis meses de idade (Hoskins, 1997). No Brasil, a doença é frequente e responsável por alta taxa de mortalidade em cães jovens. $\mathrm{O}$ objetivo deste estudo foi avaliar os efeitos da nutrição enteral enriquecida com glutamina sobre a evolução clínica de cães naturalmente acometidos pela parvovirose. Para tal, realizouse um estudo prospectivo em cães com gastrenterite hemorrágica viral (GEHV) pelo parvovirus canino de ocorrência natural utilizando-se 20 animais provenientes da casuística de atendimento clínico em um hospital veterinário, entre os anos de 2005 e 2006. Entraram no estudo os animais que atenderam os seguintes critérios: idade entre dois a seis meses, presença de diarreia hemorrágica, leucopenia ao hemograma, resultado positivo no teste de detecção do parvovirus fecal pelo Elisa $^{1}$ e concordância do proprietário em internar o animal até a alta hospitalar. Dez receberam o protocolo de tratamento 1 (grupo 1) e os outros 10, o protocolo de tratamento 2 (grupo 2). A única diferença entre os protocolos de tratamento foi a adição do aminoácido glutamina na solução de nutrição enteral para os animais do grupo 2. A relação de todos os animais que participaram do experimento é apresentada na Tab. 1, e a decisão de qual protocolo terapêutico a ser utilizado foi definida por sorteio.

Recebido em 26 de fevereiro de 2008

Aceito em 6 de agosto de 2009

E-mail: prenato@ufv.br

Apoio: FAPEMIG, MG
O protocolo terapêutico comum a ambos os grupos foi constituído pela administração de fluidos intravenosos, antibióticos, antieméticos, antiparasitários e nutrição enteral com a infusão de pequenas quantidades de nutrientes por sonda nasoesofágica.

Para nutrição enteral, foi empregada uma solução comercial reidratante isosmolar ${ }^{2}$, contendo eletrólitos e glicose. Nos animais do grupo 2, foi adicionado a essa solução o aminoácido glutamina $^{3}$, na dose de $500 \mathrm{mg} / \mathrm{kg}$. A administração foi realizada por uma sonda nasoesofágica conectada ao equipo e frasco contendo a solução. Como sonda nasoesofágica foi adaptada uma sonda uretral ${ }^{4}$ número 4 ou 6 conforme o tamanho do animal. A colocação da sonda foi feita diariamente de forma alternada em cada narina. Antes da introdução da sonda, foi instilada $0,5 \mathrm{ml}$ de lidocaína ${ }^{5}$ na narina escolhida com objetivo de minimizar o desconforto da passagem da sonda. Para o posicionamento correto no esôfago distal, o comprimento da sonda foi estimado externamente a partir da distância da narina até o $10^{\circ}$ espaço intercostal. A fixação da sonda foi feita com ponto de sutura na pele da face do animal, e o local do ponto de sutura recebeu anestesia prévia com lidocaína.

\footnotetext{
${ }^{1}$ Snap Parvo ${ }^{\circledR}$ - BioBrasil - São Paulo, Brasil.

${ }^{2}$ Pedialyte solução - Abbott - São Paulo, Brasil.

${ }^{3}$ Glutamina em pó - Mendicamentus farmácia de manipulação - Viçosa, Brasil.

${ }^{4}$ Sonda uretral descartável siliconizada - Mark Méd. Bragança Paulista, Brasil.

${ }^{5}$ Lidojet - União Química- São Paulo, Brasil.
} 
A solução para nutrição enteral foi infundida à velocidade de $0,25 \mathrm{~mL} / \mathrm{kg} /$ hora realizada por oito horas a cada 24 horas. Para controle da baixa velocidade de infusão, foi utilizada uma bomba de infusão ${ }^{6}$. A administração da nutrição enteral foi mantida durante todo o período de internação.

Para analisar o efeito da adição de glutamina na nutrição enteral, foram confrontados as taxas médias de mortalidade, a tempo de internação e o percentual de ganho de peso entre os animais dos grupos 1 e 2 . Os resultados foram comparados pelo teste exato de Fisher ao nível de significância de $5 \%$.

A taxa de mortalidade foi de $20 \%$ no grupo 1 e $10 \%$ no grupo 2 . Pelo teste exato de Fisher, o valor de $\mathrm{P}$ foi 1,00 e a $5 \%$ de significância não houve diferença entre os dois grupos em relação à taxa de mortalidade. A não existência de diferença significativa entre os grupos pode ser explicada por algumas hipóteses. Primeiramente, o protocolo de tratamento intensivo realizado em ambos os grupos foi bastante semelhante, e a única diferença foi o acréscimo do aminoácido glutamina. A presença de nutrientes no intestino estimulou o sistema imune local a secretar IgA, aumentou a produção de muco e manteve a massa intestinal funcional, reduzindo a permeabilidade intestinal e o potencial de translocação bacteriana conforme sugeriram Devey e Crowe (2000) e Mohr et al. (2003). Portanto, é possível que a presença de glicose e eletrólitos na luz intestinal tenha contribuído, de maneira similar à glutamina, para a manutenção da função intestinal.

Vários estudos em medicina humana e com animais de laboratório têm demonstrado que a glutamina melhora a função da barreira intestinal, diminuindo a permeabilidade e aumentando a cicatrização da mucosa (Souba, et al. 1990; Li et al., 1994; Remillard et al., 2000). Desse modo, neste trabalho não foi possível demonstrar o efeito benéfico da suplementação de glutamina na alimentação enteral. É possível que o efeito não ocorreu em razão do pequeno volume administrado na nutrição enteral, no entanto, esse volume não pode ser aumentado, pois pode exacerbar o vômito e a diarreia.

Palavras-chave: cão, parvovirose, gastrenterite hemorrágica, glutamina

\begin{abstract}
The effect of the addition of glutamine aminoacid in a solution to early enteral nutrition in dogs with hemorrhagic gastroenteritis by parvovirus (GEHV) was evaluated in a prospective study with 20 dogs. The animals were randomly separated in two groups of treatment. Animals in group 1 did not receive glutamine and in group 2 received glutamine by enteral solution. The mortality rate was 20\% in group 1 and $10 \%$ in group 2, but difference was not statistically significative. The addition of glutamine in a solution to enteral nutrition did not change mortality rate.
\end{abstract}

Keywords: dog, parvovirosis, hemorrhagic gastroenteritis, glutamine

\section{AGRADECIMENTOS}

À Fundação de Amparo à Pesquisa do Estado de Minas Gerais (FAPEMIG), pelo apoio financeiro para a execução do presente trabalho.

\section{REFERÊNCIAS BIBLIOGRÁFICAS}

DEVEY, J.J.; CROWE, D.T. Microenteral nutrition. In: BONAGURA, J.D. Kirk's current veterinary therapy. XIII. Small animal practice. Philadelphia: Saunders, 2000. p.136-140.
HOSKINS, J.D. Update on canine parvoviral enteritis. Vet. Med., p.694-709, 1997.

LI, J.; LANGKAMP-HENKEN, B.; SUZUKI, K. et al. Glutamine prevents parenteral nutritioninduced increases in intestinal permeability. $J$. Parenter. Enter. Nutr., v.18, p.303-307, 1994.

MOHR, A.J.; LEISEWITZ, A.L.; JACOBSON, L.S. et al. Effect of early enteral nutrition on intestinal permeability, intestinal protein loss, and outcome in dogs with severe parvoviral enteritis. J. Vet. Intern. Med., v.17, p.791-798, 2003.

${ }^{6}$ LF 2001 - Lifemed 
REMILLARD, R.L.; ARMSTRONG, P.J.; DAVENPORT, D.J. Assisted feeding in hospitalized patients: enteral and parenteral nutrition. In: HAND, M.S.; TRATCHER, C.D.; REMILLARD, R.L. et al. Small animal clinical nutrition. 4.ed. Topeka, KA: Mark Morris Associates, 2000. p.351-390.
SOUBA, W.W.; KLIMBERG, V.S.; PLUMLEY, D.A. et al. The role of glutamine in maintaining a healthy gut and supporting the metabolic response to injury and infection. J. Surg. Res., v.48, p.383, 1990. 